\title{
Fotodermatosis mediadas inmunológicamente
}

\author{
Immunologically mediated photodermatoses
}

\author{
Claudia Juliana Mariaca', Rodrigo Nuñez ${ }^{2}$ \\ 1. Médica dermatóloga, Universidad Pontificia Bolivariana, Medellín, Colombia \\ 2. Médico dermatólogo; profesor de Dermatología, Universidad Pontificia Bolivariana, Medellín, Colombia
}

\section{RESUMEN}

Las fotodermatosis son enfermedades de la piel inducidas o exacerbadas por la radiación electromagnética (radiación ultravioleta, luz visible) y se pueden dividir en cinco grupos: fotodermatosis mediadas inmunológicamente, fotodermatosis secundarias a agentes exógenos, fotodermatosis secundarias a agentes endógenos y enfermedades causadas por defecto en la reparación del ADN (genodermatosis). En este artículo, se revisa el primer grupo de fotodermatosis, las cuales incluyen la erupción solar polimorfa, el prurigo actínico, la dermatitis actínica crónica, la urticaria solar y la hidroa vacciniforme.

PALABRAS CLAVE: fotosensibilidad, rayos ultravioleta, prurigo actínico, urticaria solar, hidroa vacciniforme.

\section{SUMMARY}

Photodermatoses are skin diseases induced or exacerbated by the electromagnetic radiation (ultraviolet radiation, visible light and infrared radiation) and they can be divided into five groups: immunologically mediated photodermatoses, photodermatoses secondary to exogenous agents, photodermatoses secondary to endogenous agents and diseases caused by a defect in the reparation of DNA (genodermatoses). In this article, we will review the first group of photodermatoses, which includespolymorphous light eruption, actinic prurigo, chronic actinic dermatitis, solar urticarial and hydroa vacciniforme.

KEY WORDS: Photosensitivity disorders, ultraviolet rays, actinic prurigo, solar urticaria, hydroa vacciniforme, polymorphic light eruption.

Las fotodermatosis son enfermedades de la piel inducidas o exacerbadas por la radiación electromagnética (incluye la radiación ultravioleta y la luz visible) y se pueden dividir en los siguientes cinco grupos.

1. Dermatosis mediadas inmunológicamente. Previamente se conocían como fotodermatosis idiopáticas. Representan un grupo heterogéneo de trastornos dermatológicos causados por la radiación óptica, en particular, la radiación ultravioleta A (UVA). Su etiopatogenia probablemente está explicada por mecanismos inmunológicos, autoinmunidad y predisposición genética. La más común de estas es la erupcion solar porlimorfa.

2. Fotodermatosis secundarias a agentes exógenos. Incluyen las reacciones fototóxicas y las reacciones fotoalérgicas.
Correspondencia:

Claudia Juliana Mariaca

Email:

julianamariaca@hotmail.com

Recibido: 5 de julio de 2015

Aceptado: 23 de noviembre 2015

No se reportan conflictos de interés. 
3. Fotodermatosis secundarias a agentes endógenos. Son aquellas como las porfirias.

4. Enfermedades causadas por defecto en la reparación del ADN (genodermatosis). Incluyen el xeroderma pigmentoso y la tricotiodistrofia.

5. Trastornos fotoagravados. Incluyen aquellas como el lupus eritematoso, la dermatomiositis, la rosácea, la dermatitis atópica y la dermatitis seborreica. Estos ocurren independiente e la exposición a la radiación ultravioleta, pero se pueden empeorar o exacerbar si hay exposición a esta ${ }^{1-6}$.

Recordemos que la radiación ultravioleta se divide en radiación ultravioleta $B$ (UVB), con un espectro de onda de 290 a $320 \mathrm{~nm}$, con el cual ocurren la quemadura solar y la síntesis de vitamina D, y la UVA, cuyo espectro va de 320 a $400 \mathrm{~nm}$, y que, a su vez, se subdivide en UVA1 (340-400 nm) y UVA 2 (320-340 nm). La UVA es responsable del bronceado, el fotoenvejecimiento y la fotosensibilidad inducida por medicamentos. La banda más corta de la luz ultravioleta es la radiación ultravioleta $\mathrm{C}$ (UVC), la cual es filtrada completamente por la capa de ozono. Solo una porción limitada del espectro solar alcanza la piel e incluye $2 \%$ de radiación ultravioleta, $32 \%$ de luz visible y $66 \%$ de luz infrarroja. La fotosensibilidad cutánea se produce por la existencia de moléculas llamadas cromóforos, que absorben la radiación ultravioleta durante la exposición al sol. El cromóforo más abundante es el ADN y genera cambios relacionados con la radiación ultravioleta, como el bronceado, la quemadura solar, el envejecimiento y la carcinogénesis ${ }^{7-9}$.

Antes de tratar sobre las fotodermatosis mediadas inmunológicamente, es importante recordar los estudios fotobiológicos. Estos incluyen el fototest, la fotoprovocación y las pruebas de fotoparche.

\section{FOTOTEST}

Es la evaluación de la reacción cutánea a la UVA, la UVB y la luz visible. Se evalúan específicamente la dosis mínima de eritema para UVB y UVA, y la reacción urticante a la luz visible, la UVA y la UVB.

Dos días antes del fototest, se deben suspender los antihistamínicos y los AINE, una semana antes, los esteroides tópicos y los psoralenos, y un mes antes, la cloroquina y los inmunosupresores sistémicos.

Se usa una plantilla opaca con muchas ventanas en la piel no comprometida de la espalda, el abdomen o la porción interna del antebrazo. La piel se expone a diferentes dosis de UVA, UVB o luz visible.
Después de la exposición a la luz, la primera lectura se hace a los 20 minutos para detectar la formación de habones observados en la urticaria solar. La dosis urticante mínima es la radiación mínima que se necesita para producir un habón localizado en la zona irradiada a diferentes longitudes de onda. La segunda lectura se hace a las 24 horas, cuando se determina la dosis mínima de eritema, la cual se define como la dosis más baja de UVA o UVB que produce eritema mínimo perceptible en el sitio expuesto.

Esta prueba es importante para el diagnóstico de las fotodermatosis y para calcular la dosis inicial de la fototerapia, y es útil en el seguimiento de la enfermedad ya que ayuda a evaluar la respuesta al tratamiento $0^{2,10,11}$.

\section{FOTOPROVOCACIÓN}

Consiste en la exposición repetida de un área de la piel a una dosis preestablecida de radiación, con el objetivo de reproducir las lesiones clínicas de la entidad que se desea estudiar. Es particularmente útil en la erupción solar polimorfa, así como en el prurigo actínico.

Para practicar esta prueba, se expone un mismo sitio de la piel durante tres a cuatro días consecutivos. Se usa UVA, UVB o radiación solar. La dosis inicial es el $80 \%$ de la dosis mínima de eritema y se aumenta 10 a $20 \%$ en los siguientes días. A diferencia del fototest, se debe practicar en piel previamente afectada, ya que, si hace en piel no comprometida, puede dar resultados falsos negativos. La lectura se hace inmediatamente y hasta 72 horas después de la última radiación².

\section{FOTOPARCHE}

Se usa en caso de que la historia clínica oriente hacia un alérgeno de fotocontacto; tiene poco valor en la erupción solar polimorfa y en la urticaria solar. Es similar a las pruebas de parche estándar; se usa la misma serie de alérgenos por duplicado en la espalda, se ocluyen con una cinta opaca y se mantienen cubiertos por 24 a 48 horas, Posteriormente, se descubre el panel de la derecha, se hace una primera lectura y se irradia con una dosis de $5 \mathrm{~J} / \mathrm{cm}^{2}$ de UVA o el $50 \%$ de la dosis mínima de eritema. Se hace una nueva lectura a las 48 horas de irradiación y se pueden hacer lecturas adicionales a las 72 o 96 horas: uno de ellos sirve como control, el cual no es irradiado y el segundo se irradia a las $24^{5}$.

\section{ERUPCIÓN SOLAR POLIMORFA}

Es la fotodermatosis mediada inmunológicamente más común en niños y en adultos ${ }^{11-13}$. 
FIGURA 1. Pápulas eritematosas que confluyen en el dorso de los antebrazos y las manos (cortesía de Luz Marina Gómez).

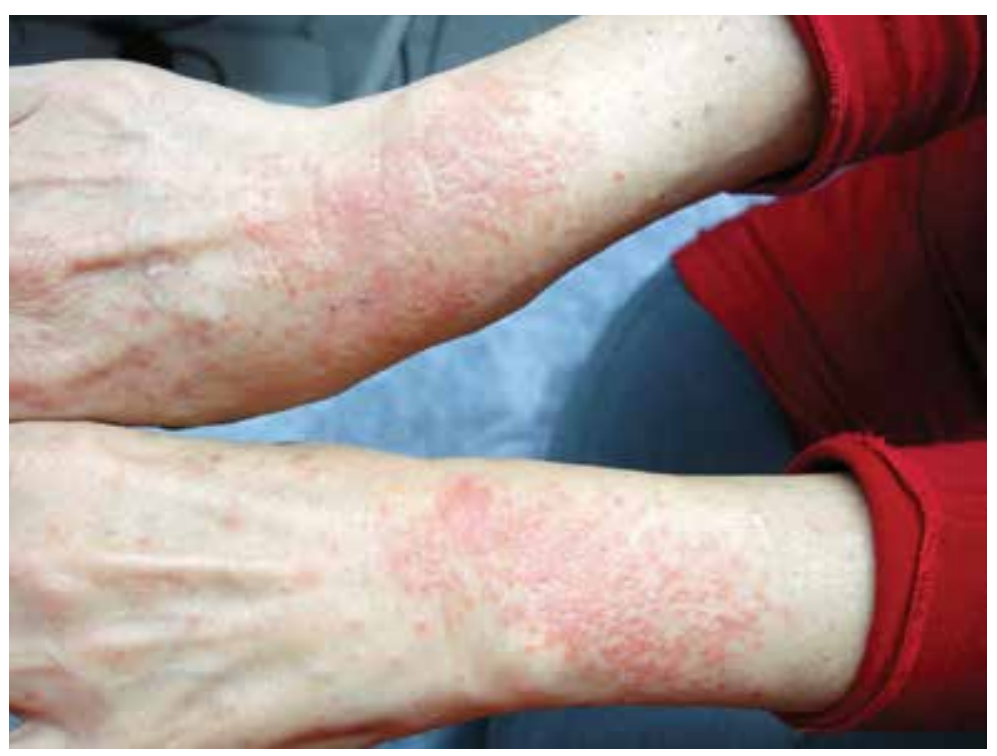

\section{EPIDEMIOLOGÍA}

Afecta principalmente a las mujeres en la segunda y tercera década de la vida, con una relación mujer a hombre de 4:1. La mayoría de los casos se inician en las primeras tres décadas de la vida, aunque hasta el $10 \%$ de los casos pueden iniciarse antes de los 14 años. Afecta todos los fototipos y razas, reportándose una mayor prevalencia en las personas con fototipo I (33,4 \%). Tiene una amplia distribución geográfica, aunque es más frecuente en climas templados y durante la primavera y el verano, con mayor prevalencia en latitudes norte, lo que indica la importancia de la adaptación de la piel a la radiación ultravioleta (hardening) secundaria a la exposición constante en climas soleados. La mayoría de los pacientes presentan recaídas cuando hay mayor exposición solar ${ }^{1,14}$.

\section{PATOgÉnesis}

En condiciones normales, la radiación ultravioleta produce un cambio de citocinas que favorece la respuesta de los linfocitos Th2 y la disminución de las células de Langerhans en la epidermis, y también, la aparición de células $\mathrm{CD}_{3} 6^{+} \mathrm{CD}_{11} \mathrm{~b}^{+} \mathrm{CD} 1$ - (subpoblación de macrófagos). Todo esto se traduce en una supresión inmunitaria. En los estudios de pacientes con esta enfermedad se sugiere que hay una resistencia a la supresión inmunitaria inducida por la radiación ultravioleta ${ }^{14}$.

Se ha planteado, además, que la radiación ultravio- leta es capaz de modificar moléculas orgánicas, como proteínas y ADN, creando nuevas moléculas inmunógenas que el sistema inmunitario puede reconocer como ajenas. Hasta el momento no ha sido posible identificar el antígeno, pero se ha sugerido que podría tratarse de la proteína de choque térmico 65 , ya que se identificó en un estudio en el cual usaron biopsias de lesiones de erupción solar polimorfa y encontraron un aumento de la expresión de esta proteína en los queratinocitos epidérmicos de los pacientes y no de los controles ${ }^{14,15}$.

Igualmente, los factores genéticos parecen jugar un papel importante. Los estudios sugieren un modelo poligénico. Se han encontrado antecedentes familiares de primer grado presentes en el $12 \%$ de los gemelos afectados, en comparación con $4 \%$ de los gemelos no afectados. La anormalidad heredada parecer ser una resistencia a la supresión que normalmente se produce por la radiación ultravioleta. Como consecuencia, no hay una inmunosupresión después de la exposición a la radiación ultravioleta (comparada con personas normales), lo que produce una reacción de hipersensibilidad retardada contra moléculas endógenas alteradas por la radiación ultravioleta ${ }^{16}$.

También se han propuesto factores hormonales. Comparadas con los hombres, las mujeres son relativamente resistentes a los efectos inmunosupresores de la radiación ultravioleta, requiriendo más de tres veces de radiación para alcanzar el mismo nivel de inmunosupresión que los hombres. En parte, esto podría explicar por qué 
hay una mayor incidencia de erupción solar polimorfa en las mujeres. El mecanismo exacto no está claro, pero se ha sugerido que la hormona femenina $17 \beta$ estradiol podría estar implicada, ya que limita la liberación de IL10 de los queratinocitos, previniendo la inmunosupresión inducida por la radiación ultravioleta. Se ha demostrado que, al bloquear los receptores de estrógenos, se puede exacerbar la inmunosupresión causada por la radiación ultravioleta, lo cual sugiere un rol importante de los receptores de estrógenos en la protección solar ${ }^{14}$.

\section{CLÍNICA}

Como su nombre lo dice, las lesiones son de morfología variable, incluyendo formas papular, pápulo-vesicular, en placa, urticante, vesículo-ampollosa, hemorrágica, eccematosa, de tipo eritema multiforme, similares a picaduras de insecto y prurigo. De las anteriores, las formas más comunes son la papular, la pápulo-vesicular y en aquella en placa (FIGURA 1). Aunque la forma de presentación varía de paciente a paciente, en uno solo las lesiones son usualmente monomorfas. Las lesiones se desarrollan desde pocas horas a días después de la exposición a la luz solar; inicialmente hay prurito y luego aparecen lesiones en las áreas expuestas al sol, especialmente, la V del escote, el cuello y las áreas extensoras de los brazos. La cara y el dorso de las manos rara vez están comprometidos, probablemente porque se exponen frecuentemente al sol. Las lesiones mejoran sin dejar cicatrices pocos días después (generalmente, en dos semanas), si se evita la exposición solar, ${ }^{7,17}$.

Mientras el verano progresa y después de exposiciones repetidas, muchos pacientes experimentan un efecto de adaptación llamado hardening, que significa que las lesiones ocurren menos frecuentemente o son menos serias, lo que permite que puedan tolerar exposición solar prolongada. Este efecto parece ser específico de la erupción solar polimorfa y no está presente en otras fotodermatosis idiopáticas, excepto en algunos casos de urticaria solar. En otras ocasiones, se puede presentar agravamiento progresivo 8,14 .

Otras formas de presentación menos comunes, son las siguientes.

- Púrpura solar. Es una variante rara con cambios purpúricos principalmente en las piernas ${ }^{18}$.

- Erupción juvenil de primavera. Afecta principalmente a los niños entre los 10 y los 12 años. Aparece durante la primavera. Se caracteriza por pápulo-vesículas pruriginosas y eritematosas que se vuelven costras, las cuales curan sin cicatriz y se localizan en las orejas. Generalmente, hay resolución espontánea al finalizar la adolescencia ${ }^{19,20}$.

- Polimorfa. No se acompaña de erupción y se caracteriza por prurito intenso en áreas expuestas, sin cambios visibles en la piel $^{20}$.

\section{RELACIÓN CON LUPUS ERITEMATOSO}

En algunos estudios se ha sugerido que la erupción solar polimorfa y el lupus eritematoso pueden compartir una patogenia común. En algunos casos, las lesiones de piel del lupus eritematoso son casi indistinguibles de las lesiones de la erupción solar polimorfa. La presencia de ANA fue uno de los criterios usados inicialmente para dis-

\begin{tabular}{|c|c|c|}
\hline EXAMEN & RESULTADOS & COMENTARIOS \\
\hline HISTOLOGÍA & $\begin{array}{c}\text { Infiltrado linfocítico perivascular en dermis. } \\
\text { Epidermis normal o espongiosis leve, paraqueratosis focal } \\
\text { o acantosis. } \\
\text { Ocasionalmente, degeneración vacuolar de la lámina } \\
\text { basal. }\end{array}$ & $\begin{array}{c}\text { Los hallazgos varían según el tipo de } \\
\text { lesión. }\end{array}$ \\
\hline \multicolumn{3}{|l|}{ FOTOTEST } \\
\hline $\begin{array}{l}\text { UVA } \\
\text { UVB } \\
\text { Luz visible }\end{array}$ & $\begin{array}{c}\text { Dosis mínima de eritema, normal o disminuida } \\
\text { Dosis mínima de eritema, normal o disminuida } \\
\text { Normal }\end{array}$ & $\begin{array}{l}\text { En la mayoría, la UVA es la responsable. } \\
\text { En ocasiones, lo son la UVA y la UVB. }\end{array}$ \\
\hline $\begin{array}{c}\text { TEST DE } \\
\text { FOTOPROVOCACIÓN }\end{array}$ & Positivo, 48 a $90 \%$ & Sin correlación con la gravedad \\
\hline LABORATORIO & $\begin{array}{l}\text { Hemoleucograma, niveles de porfirinas, anticuerpos } \\
\text { antinucleares, anti-Ro/La }\end{array}$ & $\begin{array}{l}\text { Negativos } \\
\text { Se usan para excluir otras dermatosis } \\
\text { (lupus eritematoso). }\end{array}$ \\
\hline
\end{tabular}

TABLA 1. Diagnóstico de erupción solar polimorfa. 
tinguir estas dos entidades, pero en estudios que datan del 2008 se ha demostrado que 14 a $19 \%$ de los pacientes con erupción solar polimorfa pueden tener títulos altos de ANA en ausencia de síntomas aparentes de lupus. En 2001, Millard, et al., describieron una mayor prevalencia de la erupción solar polimorfa entre los familiares de enfermos de lupus que en la población general, por lo que indicaron que podía existir una base genética común para estas dos entidades. Las lesiones de erupción solar polimorfa pueden preceder el desarrollo del lupus. Se ha propuesto la progresión de erupción solar polimorfa a lupus; sin embargo, en estudios a largo plazo de pacientes con erupción solar polimorfa, no se han encontrado un aumento de la tasa de transición a lupus 14,21-26. $^{14}$

\section{Diagnóstico}

TABLA $1^{5,27,28}$

\section{DIAGNÓSTICO DIFERENCIAL}

- Urticaria solar.

- Lupus eritematoso.

- En algunas ocasiones, el eritema multiforme asociado al virus del herpes puede simular la erupción juvenil de primavera.

- Dermatitis de contacto fotoalérgica, particularmente a protectores solares: esta entidad se puede distinguir con las pruebas de parche y de fotoparche.

- Dermatitis de contacto por agentes aerotransportados.

- $\quad$ Prurigo simple $e^{8,14}$.

\section{TRATAMIENTO}

La selección del tratamiento depende de la frecuencia, la duración, la gravedad y el grado de restricción de las actividades de la vida diaria. Se divide en tratamiento dirigido a acortar las exacerbaciones y tratamiento profiláctico.

Afortunadamente, la mayoría de los casos son leves y mejoran con medidas básicas de protección solar, como evitar el sol, y usar ropa protectora y protectores solares de amplio espectro. Cuando hay exacerbaciones leves, se usan los esteroides tópicos solos o en combinación con antihistamínicos orales, para disminuir la inflamación y el prurito, y acortar la duración de la erupción ${ }^{14,27}$.

Se ha demostrado que los esteroides orales son mejores que el placebo para controlar la enfermedad, y se consideran el tratamiento de primera línea en pacientes con enfermedad moderada a grave que no se controlan con las medidas de protección solar y esteroides tópicos. Se pueden usar cursos cortos de esteroides orales (o,6 a 1,0 mg/kg por 7 a 10 días) en pacientes con recurrencias ocasionales moderadas a graves, 0 incluso, en algunos pacientes, como tratamiento profiláctico para prevenir la enfermedad en caso de que se vayan a exponer al sol, como por ejemplo, durante las vacaciones $(<0,5 \mathrm{mg} / \mathrm{kg} \text { por } 5 \text { a } 7 \text { días })^{28,29}$.

Los antipalúdicos anteriormente considerados como tratamiento de primera línea, ahora están indicados como de segunda línea. Los estudios iniciales demostraron su eficacia ya que aumentaban la tolerancia a la luz solar, y disminuían la erupción y el prurito, pero, los estudios relacionados en el tratamiento de la erupción solar polimorfa no han reproducido estos resultados. Algunos autores creen que es posible que los estudios iniciales hayan incluido pacientes con variantes de lupus eritematoso con fotosensibilidad diagnosticadas erróneamente como erupción solar polimorfa. Actualmente, están indicados en pacientes con erupción solar polimorfa que no mejoran con el tratamiento de primera línea y con las medidas generales de protección solar. Algunos autores recomiendan $400 \mathrm{mg}$ diarios de hidroxicloroquina pocos días antes de la exposición al sol y reducir la dosis a $200 \mathrm{mg} /$ día una vez se obtiene estabilidad clínica ${ }^{29-32}$.

En caso de síntomas graves que no mejoren con esteroides orales ni antipalúdicos, se puede considerar el uso de azatioprina o ciclosporina como tratamiento de tercera línea ${ }^{14}$.

En cuanto al tratamiento profiláctico, la fototerapia es de elección en casos graves, para aquellos pacientes que no tienen una desensibilización natural con la luz solar. Se suministra dos a tres veces por semana durante 4 a 6 semanas, y su efecto suele durar entre 4 y 6 semanas, por lo que se le debe sugerir al paciente exponerse al sol una a dos veces por semana durante 15 minutos sin protección durante el resto del verano. La dosis inicial de UVB de banda estrecha (UVB BE) es del 50 al $70 \%$ de la dosis mínima de eritema, incrementando la dosis 10 a $15 \%$ en cada tratamiento. Para la PUVA se usa 8-metoxipsoraleno a una dosis de o,5 a $0,6 \mathrm{mg} / \mathrm{kg}$, una a tres horas antes de la exposición; la dosis inicial de la UVA varía de 0,5 a $3 \mathrm{~J} / \mathrm{cm}^{2}$, dependiendo del fototipo o de la dosis fototóxica mínima. En algunos casos se puede usar prednisona oral (0,5 a $1 \mathrm{mg} / \mathrm{kg}$ ) en los primeros 7 a 10 días de la fototerapia, para minimizar las exacerbaciones que pueden ocurrir en algunos pacientes, pero, en raras ocasiones, requieren la suspensión de la fototerapia. La eficacia de la PUVA y la UVB de banda estrecha son comparables, $70 \%$ Vs. $63 \%$, respectivamente. Sin embargo, se prefiere la UVB de banda estrecha dado que tiene un mejor perfil de seguridad ${ }^{11,27,33}$. 
Otros tratamientos, como Polypodium leucotomos, que tiene acción antioxidante y antiinflamatoria, pueden disminuir los síntomas y las lesiones en piel. En un estudio controlado con placebo de asignación aleatoria de 13 pacientes, se demostró que el calcipotriol tópico puede ser útil en la prevención de la enfermedad cuando se usa antes de la exposición a la radiación, lo que sugiere que podría ser útil en la profilaxis de la enfermedad 34,35 .

\section{PRURIGO ACTÍNICO}

Es una enfermedad por fotosensibilidad poco común. Fue inicialmente clasificada como una variante de la erupción solar polimorfa, pero existe evidencia clínica, histológica, epidemiológica e inmunogénica de que es una entidad diferente. Inicialmente se denominó 'prurigo del verano de Hutchinson' o 'erupción solar polimorfa hereditaria', pero, en 1961, el doctor Fabio Londoño le dio el nombre de prurigo actínico ${ }^{36,37}$.

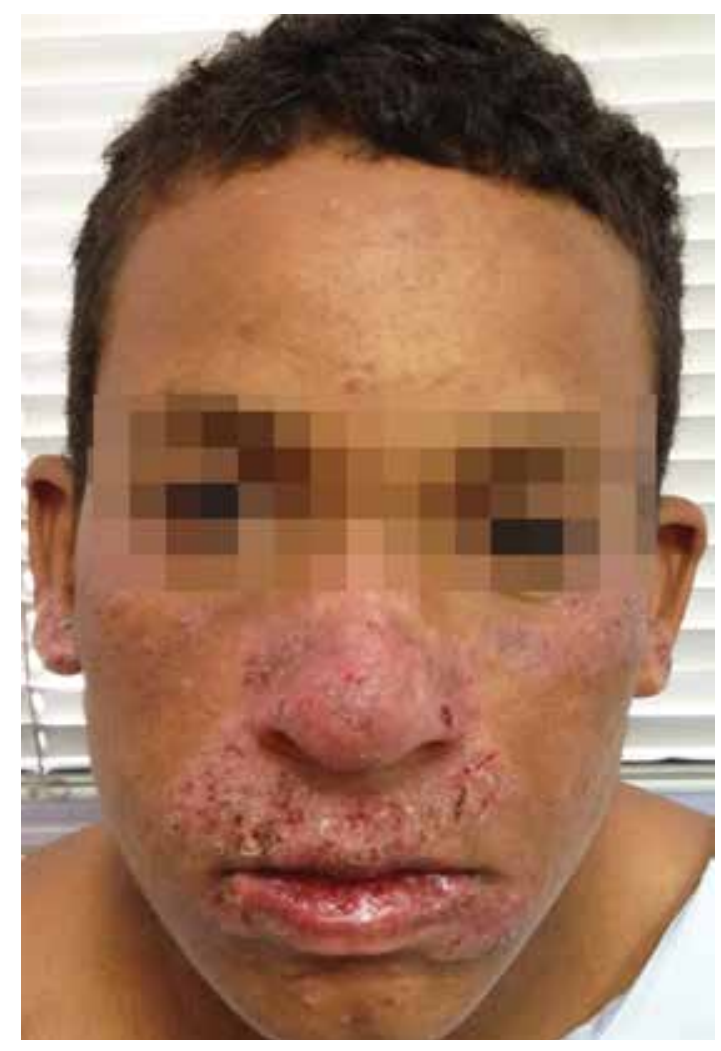

FiguRA 2. Placas eritematosas en algunos sitios con costras y 'liquenificación', localizadas en las orejas, el dorso de la nariz, las mejillas, el labio superior y el inferior (cortesía de Ángela Londoño)

\section{EPIDEMIOLOGÍA}

Afecta principalmente tribus indígenas de Suramérica, Centroamérica y Norteamérica, y mestizos de América Latina, particularmente, en México, Colombia, Perú, Bolivia, Ecuador, Guatemala y Honduras. Es poco común en caucásicos. En los indios chimila de Colombia, la prevalencia es del $8 \%$. La enfermedad predomina en fototipos III a V, y es más común en mujeres que en hombres, a excepción de los indios chimila y en los asiáticos, entre quienes los hombres son los más afectados. Se presenta usualmente entre los 4 y los 8 años; en la mayoría de los casos se inicia antes de los 20 años, aunque hay casos de inicio en la edad adulta. Dependiendo de la población estudiada, es común encontrar personas con antecedente familiar de la enfermedad ${ }^{36,38}$.

\section{PATOgÉnesis}

Su patogénesis es desconocida, pero se cree que es una reacción de hipersensibilidad retardada a un autoantígeno que aún no ha sido identificado, el cual probablemente es inducido por la radiación ultravioleta.

$\mathrm{Al}$ igual que en la erupción solar polimorfa, se ha demostrado que hay persistencia de las células de Langerhans en la epidermis después de la exposición a la radiación ultravioleta, por lo que las células presentadoras de antígeno permanecen en la epidermis, generando una reacción inflamatoria persistente $\mathrm{e}^{8,17,33,36,39,40}$.

Se han descrito dos variantes: una en indios nativos de América que representa una forma familiar, y una variante esporádica que se ve en personas caucásicas de Europa y en la raza china. En ambas formas se ha encontrado una clara relación con el HLA, particularmente con el HLA DRB1` ${ }^{\star} 407$. Este comúnmente se encuentra en los americanos, pero es poco común en los caucásicos europeos. La distribución geográfica de este alelo puede explicar por qué el prurigo actínico es más común en algunos lugares de Norteamérica, Centroamérica y Suramérica. Aunque esta enfermedad está estrechamente relacionada con el HLA, puede ocurrir en su ausencia ${ }^{36,41-43}$.

\section{CLÍNICA}

Las lesiones son polimorfas en un mismo paciente y se caracterizan por pápulas planas y poligonales muy pruriginosas, algunas con costras hemáticas, las cuales pueden unirse para formar placas 'liquenificadas'. (FIGURA 2). Las lesiones curan con hipopigmentación o hiperpigmentación residual y, en raras ocasiones, con formación de cicatrices. Las lesiones se localizan casi exclusivamente en las áreas faciales 

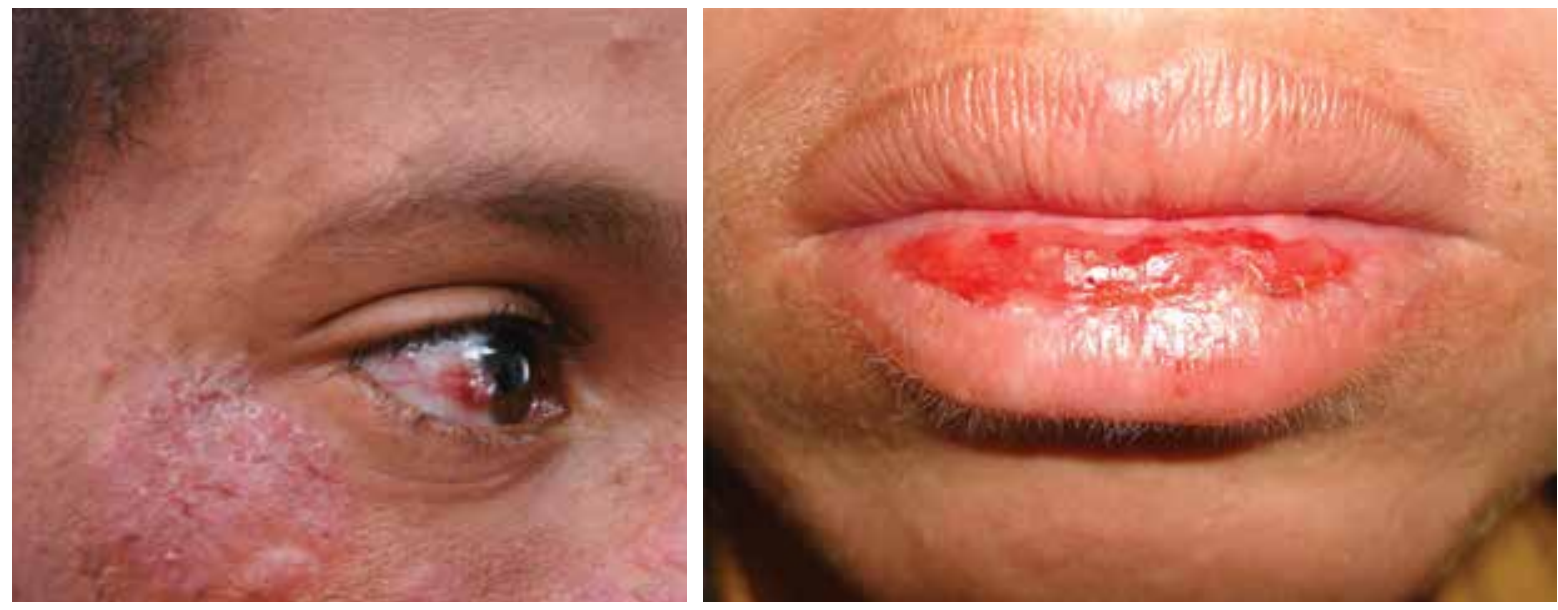

FIGURA 3. Pseudopterigio del ojo derecho (cortesía de Luz Marina Gómez).

expuestas (cejas, región malar, puente nasal, labios y orejas), el cuello, la V del escote, las superficies extensoras de los brazos y antebrazos, y el dorso de las manos. Se ha descrito compromiso de áreas cubiertas hasta en $40 \%$ de los pacientes, pero con lesiones menos serias ${ }^{17,37,38}$.

El compromiso de los ojos ocurre hasta en $62 \%$ de los casos y se inicia con hiperemia, fotofobia y epífora que, posteriormente, progresa a hipertrofia de papilas y pseudopterigio (FIGURA 3).

La queilitis se presenta en 33 a $85 \%$ de los casos y se localiza principalmente en el labio inferior o, en raras ocasiones, en el área central del labio superior. Se puede presentar con edema, descamación, fisuras, formación de costras, hiperpigmentación, erosión y ulceración (FIGURA 4). En algunos pacientes, la queilitis puede ser la única manifestación de la enfermedad y se ha reportado hasta en $27,6 \%$ de los $\operatorname{casos}^{36,44-48}$.

\section{DIAGNÓSTICO}

TABLA $2^{36,49}$

\section{DIAGNÓSTICO DIFERENCIAL}

Se deben considerar:

- Dermatitis atópica por fotosensibilidad. El antecedente personal o familiar de atopia, el inicio más temprano y una buena reacción a los esteroides y emolientes, orientan a su diagnóstico.

- Dermatitis actínica crónica. Hace parte del diag- nóstico diferencial, aunque se presenta principalmente en hombres mayores.

- Erupción solar polimorfa. A diferencia del prurigo actínico, no se acompaña de compromiso ocular ni de los labios ${ }^{1,366-38}$.

\section{TRATAMIENTO}

El manejo consiste en evitar la exposición solar, usar ropa protectora, sombreros de ala ancha y gafas de protección para la luz ultravioleta, aplicar labiales con protección solar y usar protector solar de amplio espectro. Hay que recordar que la UVA puede pasar a través de las ventanas, por lo que puede ser útil el uso de películas de protección en las ventanas de la casa y los carros. Todos los pacientes deben ser remitidos a oftalmología ${ }^{36,37}$.

Los esteroides tópicos potentes son útiles para mejorar el prurito y las lesiones eccematosas. Como alternativa a largo plazo, se pueden usar los inhibidores de la calcineurina. Si el prurito es intenso, están indicados los antihistamínicos $^{49,50}$.

El tratamiento de primera línea es la talidomida. Su efectividad puede ayudar a confirmar el diagnóstico de prurigo actínico, ya que los pacientes, por lo general, mejoran rápidamente. La dosis inicial es de 100 a 300 mg al día, con disminución progresiva hasta alcanzar la dosis mínima efectiva, 50 a $100 \mathrm{mg}$ a la semana. En 20 a $50 \%$ de los pacientes, se puede presentar neuropatía periférica predominantemente sensitiva, generalmente, en el primer año de tratamiento; al suspender el medica- 


\begin{tabular}{|c|c|c|}
\hline EXAMEN & RESULTADOS & COMENTARIOS \\
\hline HISTOLOGÍA & $\begin{array}{l}\text { Hiperqueratosis, acantosis irregular, telangiectasias } \\
\text { superficiales. Infiltrado inflamatorio crónico linfocítico } \\
\text { perivascular. } \\
\text { Queilitis folicular: infiltrado linfocítico denso con } \\
\text { folículos linfoides bien formados. Un patrón similar se } \\
\text { encuentra en la conjuntiva. }\end{array}$ & $\begin{array}{l}\text { Son específicos los de las biopsias de } \\
\text { labio y conjuntivas, no los de piel. }\end{array}$ \\
\hline \multicolumn{3}{|l|}{ FOTOTEST } \\
\hline $\begin{array}{l}\text { UVA } \\
\text { UVB } \\
\text { Luz visible }\end{array}$ & $\begin{array}{c}\text { Dosis mínima de eritema, normal o disminuida } \\
\text { Dosis mínima de eritema usualmente normal } \\
\text { Normal }\end{array}$ & $\begin{array}{l}\text { La mayoría tienen dosis mínima de } \\
\text { eritema de UVA disminuido. } \\
\text { En ocasiones dosis mínima de eritema } \\
\text { UVA y UVB disminuidos. }\end{array}$ \\
\hline $\begin{array}{c}\text { TEST DE } \\
\text { FOTOPROVOCACIÓN }\end{array}$ & Positivo en el $75-100 \%$ de los casos & Sin correlación con la gravedad \\
\hline LABORATORIO & $\begin{array}{l}\text { HLG, niveles porfirinas, ANAS, Anti Ro/La } \\
\text { HLA DRB }{ }^{\star} 0407\end{array}$ & $\begin{array}{l}\text { Negativos } \\
\text { Útil en el diagnóstico en los países donde } \\
\text { la prevalencia de este alelo es baja. }\end{array}$ \\
\hline
\end{tabular}

TABLA 2. diagnóstico de prúrigo actínico. HLG: hemoleucograma, ANAS: anticuerpos antinucleares.

mento, se resuelve en la mitad de ellos. La dosis diaria y la dosis acumulada son factores importantes que determinan su desarrollo. Se debe tener en cuenta, además, que una dosis única de $100 \mathrm{mg}$ los primeros 35 a 50 días del embarazo, es suficiente para causar malformaciones fetales, por lo que es obligatoria la anticoncepción adecuada, incluyendo la de los hombres ${ }^{36,51-55}$.

En los episodios agudos se pueden usar cursos cortos de esteroides orales a dosis diarias de 0,5 a $1 \mathrm{mg} / \mathrm{kg}$, aunque usualmente no producen mejoría completa de las lesiones ${ }^{49}$.

La fototerapia, particularmente la UVB BE, se ha usado exitosamente en algunos pacientes, pero su efecto es limitado. La dosis inicial es el $50 \%$ de la dosis mínima de eritema, con incrementos del $20 \%$ en cada sesión si el paciente no presenta eritema, con una frecuencia de tres veces por semana. Después de la fototerapia, se recomienda que los pacientes continúen la exposición al sol regularmente, para evitar la reaparición de las lesiones. Se pueden usar esteroides tópicos o un curso de 5 a 7 días de esteroides orales, para manejar las exacerbaciones inducidas por la fototerapia ${ }^{36,49}$.

La ciclosporina oral a dosis diarias de $2,5 \mathrm{mg} / \mathrm{kg}$ por $6 \mathrm{a}$ 8 meses y la azatioprina, 50 a $100 \mathrm{mg}$ al día por 8 meses, se han utilizado en casos graves y resistentes a otros tratamientos ${ }^{36,56}$.

La pentoxifilina, que tiene propiedades anti-TNF $\alpha$, fue reportada como efectiva para el manejo de las lesiones cutáneas y del prurito, en un estudio no controlado, a una dosis de $1.200 \mathrm{mg}$ al día por seis meses. Sin embargo, los pacientes presentaron recaída cuando se descontinuó el tratamiento ${ }^{57}$.

Los antipalúdicos, aunque pueden ser útiles en la erupción solar polimorfa, no lo son en el prurigo actínico ${ }^{36}$.

\section{Pronóstico}

El pronóstico es variable. Se ha reportado mejoría con la edad e incluso resolución espontánea en la pubertad, en particular, si el inicio de la enfermedad es temprano, aunque esto no se reporta en Latinoamérica. En las áreas soleadas, la enfermedad tiene un curso crónico y persistente; en otras latitudes, como en Canadá e Inglaterra, hay exacerbaciones durante la primavera y el verano, y mejoría en el invierno. Se ha descrito una forma de inicio en la adultez, y estos casos tienden a ser más persistentes ${ }^{8,58}$.

\section{DERMATITIS ACTÍNICA CRÓNICA}

La dermatitis actínica crónica es una fotodermatosis mediada inmunológicamente, caracterizada por lesiones eccematosas pruriginosas en áreas expuestas al sol. Recibe otros nombres, como reacción persistente a la luz, reticuloide actínico y eccema por fotosensibilidad. Los tres criterios diagnósticos principales son:

1. Erupción eccematosa persistente que predomina en áreas expuestas y en raras ocasiones se extiende a las áreas cubiertas.

2. Cambios histopatológicos indicativos de eccema crónico con cambios de tipo linfoma o sin ellos. 
3. El fototest muestra una reducción en la dosis mínima de eritema a UVA y UVB, y algunas veces, a la luz visible ${ }^{7,9,59}$.

\section{EPIDEMIOLOGÍA}

Es una de la fotodermatosis más frecuente en pacientes mayores de 50 años; usualmente, afecta a los hombres y solo de 10 a $22 \%$ de las personas afectadas son mujeres. Ocurre principalmente en climas templados y puede afectar personas de todas las razas y los fototipos; sin embargo, en Estados Unidos se ha reportado especialmente en los fototipos V y VI. Su presentación en jóvenes es infrecuente, excepto en aquellos con antecedentes personales de eccema atópico y VIH. Otros factores asociados son las actividades al aire libre y la dermatitis de contacto. No hay evidencia de predisposición genética ${ }^{60-62}$.

\section{PATOgÉnesis}

No ha sido completamente elucidada. Probablemente representa una reacción de hipersensibilidad retardada frente a un alérgeno cutáneo endógeno inducido por la luz solar. El antígeno responsable no ha sido identificado, pero los estudios indican que puede ser el ADN, el ARN o moléculas asociadas $59,63,64$.

\section{CLÍNICA}

El cuadro clínico clásico es el de una dermatitis pruriginosa con cambios eccematosos extensos, 'liquenificación' y descamación. Las lesiones se localizan principalmente en las áreas expuestas de la cara, el cuero cabelludo, la espalda, el cuello, la V del escote, los antebrazos y el dorso de las manos. Es frecuente encontrar una diferencia abrupta con la ropa y en áreas no expuestas, pero, después de un tiempo, estas áreas también se pueden comprometer en el $50 \%$ de los pacientes. Menos del $10 \%$ de los casos se presentan con morfología pseudolinfomatosa y en pacientes gravemente afectados puede haber eritrodermia ${ }^{59,65}$.

\section{DiAgNóSTICO}

TABLA $3^{59,62,63}$.

\section{DIAGNÓSTICO DIFERENCIAL}

Las condiciones que se pueden confundir con la dermatitis actínica crónica, incluyen las erupciones por medicamentos, la dermatitis de contacto alérgica o fotoalérgica, el linfoma cutáneo de células T, la dermatitis atópica y las enfermedades del tejido conjuntivo ${ }^{59,66}$.

\section{EXAMEN}

HISTOLOGÍA

Espongiosis epidérmica, infiltrado linfocítico moderado superficial y profundo

RESULTADOS COMENTARIOS

\begin{abstract}
DEM disminuido
DEM disminuído

Normal o disminuido
\end{abstract}

Positiva $80 \%$

Incluir serie estándar, plantas, filtros solares.
Negativos

Pueden encontrarse células a tipo Sèzary

$+/-$
Se puede confundir con linfoma cutáneo de células T. La inmunohistoquímica ayuda a diferenciarlos.
ANAS, ANTI RO/LA
PERIFE VIH

Alergenos con más reacciones positivas: oleorresinas de plantas, metales, fragancias, colofonia, filtros solares .

Realizar cuando la enfermedad esté inactiva para evitar falsos positivos.

DAC puede ser el signo de presentación en pacientes con VIH.

TABLA 3. Diagnóstico de dermatitis actínica crónica (DAC). ANAS: anticuerpos antinucleares. 


\section{TRATAMIENTO}

La clave del manejo es la protección solar estricta. Se deben usar protectores solares de amplio espectro, con factor de protección solar mínimo de 30, camisas de manga larga y sombrero. Se puede considerar el uso de películas de protección contra la UVA en las ventanas de las casas y los automóviles. En caso de que se identifiquen alérgenos de contacto o de contacto con la luz solar, se deben evitar59.

Como tratamiento de primera línea se usan los esteroides tópicos de mediana o alta potencia, o inhibidores tópicos de la calcineurina ${ }^{67-69}$. Para la enfermedad generalizada o resistente al tratamiento, se usan medicamentos inmunosupresores. La prednisolona, 0,5 a 1 $\mathrm{mg} / \mathrm{kg}$ al día, se puede suministrar por varias semanas en los episodios agudos ${ }^{59}$.

Se han usado varias formas de fototerapia y la más aceptada es la PUVA. Se debe determinar la dosis fototóxica mínima para la dosis mínima de eritema para la UVA e iniciar la fototerapia con una dosis menor que esta, con una frecuencia de dos sesiones a la semana y aumentos del $20 \%$ cada semana. También, se ha usado la UVB de banda estrecha, iniciando con dosis de 50 a $70 \%$ de la dosis mínima de eritema, 2 a 3 sesiones por semana, con incremento del 10 al $15 \%$ en cada sesión. Se recomiendan 15 sesiones $\mathrm{y}$, posteriormente, una fase de mantenimiento con luz solar ${ }^{11}$.

En casos resistentes al tratamiento se han usado agentes ahorradores de esteroides, como la ciclosporina (3,5-5 mg/kg al día) $)^{70}$, la azatioprina (1-2,5 mg/kg al día) (71) y el micofenolato de mofetilo (25-40 mg/kg al día) (1-2 g/día $)^{72}$. Incluso, hay un reporte de caso de un paciente de 37 años que había recibido fototerapia UVA, ciclosporina y azatioprina sin mejoría, que mejoró con la talidomida (100 mg/día) con disminución gradual a 50 mg dos veces a la semana ${ }^{72}$.

\section{PRONóstico}

La dermatitis actínica crónica generalmente persiste por años. Se ha reportado resolución espontánea en 10\% de los casos a los 5 años y en $50 \%$ a los 15 años. Los pacientes con dermatitis actínica crónica tienen mayor riesgo de desarrollar dermatitis alérgica de contacto. En pocos reportes de casos se ha sugerido la posibilidad de transformación maligna de la dermatitis actínica pseudolinfomatosa o asociación con otras neoplasias malignas, pero, en un estudio en el Reino Unido de 231 pacientes, no se encontró aumento del riesgo de linfoma en un periodo de seguimiento de 20 años. Por lo tanto, no parece que la dermatitis actínica crónica sea una condición premaligna ${ }^{59,73,74}$.

\section{URTICARIA SOLAR}

Es una forma poco común de urticaria física y corresponde al $1 \%$ de todas las formas de urticaria. Se caracteriza por eritema, edema y habones que aparecen pocos minutos después de la exposición a diferentes longitudes de onda ${ }^{10,75,76}$.

\section{EPIDEMIOLOGÍA}

El inicio de la enfermedad puede ocurrir a cualquier edad, aunque es más común en mujeres en la tercera década. Afecta todas las razas. Se ha reportado su coexistencia con erupción solar polimorfa, dermatitis actínica crónica, prurigo actínico y porfiria cutánea tarda ${ }^{76-80}$.

\section{PATOgÉnesis}

La urticaria solar resulta de una reacción de hipersensibilidad inmediata de tipo I. La onda de luz activadora convierte un cromóforo aún no identificado (proantí-

\begin{tabular}{ccc}
\hline \hline EXAMEN & RESULTADOS & COMENTARIOS \\
\hline FOTOTEST & Normal o habón & La evaluación debe ser inmediatamente \\
UVA & Normal o habón & yasta 1 hora después de la radiación. \\
UVB & Normal o habón & El espectro de acción varía. Mayoría \\
luz visible visible (57\%) +/- UVA. $20 \%$ UVA + & UVB + luz visible. Casos descritos con \\
& & infrarrojo. \\
& & Resultado negativo no excluye el \\
& diagnóstico. & Excluir LE y porfirias \\
LABORATORIO & ANAS, porfirinas &
\end{tabular}

TABLA 4. Diagnóstico de urticaria solar. ANAS: anticuerpos antinucleares 
geno) a antígeno, por alteración fotoquímica. Este es reconocido por la IgE específica de este alérgeno en la superficie de los mastocitos, causando degranulación, y liberación de histamina y de otros mediadores ${ }^{76,81}$.

\section{CLÍNICA}

Los pacientes generalmente desarrollan prurito o sensación de quemazón pocos minutos después de la exposición solar, seguido de aparición de eritema y posteriormente habones a los 5 a 10 minutos de la exposición. Las lesiones se resuelven usualmente en 1 a 3 horas (menos de 24 horas). Se confinan a áreas expuestas (V del escote, brazos, antebrazos), aunque la cara y el dorso de las manos, por lo general, están respetados por el mecanismo de adaptación, ya que estas son zonas expuestas diariamente a la radicación. Algunos pacientes pueden presentar lesiones en las áreas cubiertas por penetración de la luz a través de la ropa, ya que la UVA y la luz visible pueden pasar a través de la ropa delgada ${ }^{75-77}$.

Hay una forma infrecuente llamada urticaria solar fija, en la cual los habones se desarrollan y se reproducen exclusivamente en un área fija de la piel. En ocasiones, hay síntomas sistémicos, como mareo, cefalea, síncope y, rara vez, choque anafiláctico si hay exposición de todo el cuerpo ${ }^{82,83}$.

\section{DIAGNÓSTICO}

TABLA $5^{5,76}$.

Una de las razones por la cual es difícil determinar el espectro de acción en la urticaria solar, es porque puede variar cuando se practican fototest repetidos, especialmente por la interacción potencial de las diferentes longitudes de onda, como se describe a continuación.

Espectro de inhibición. Se ha reportado hasta en $69 \%$ de las series japonesas. Cuando la piel es expuesta a longitudes de onda que inducen urticaria e, inmediatamente después o concomitantemente, a longitudes de onda mayor, la reacción urticante se puede disminuir en intensidad o, incluso, no aparecer. Podría explicar aquellos casos en los que la urticaria solar no puede reproducirse mediante fuentes artificiales, pero, sî con exposición natural, y también, aquellos con una reacción diferida (incluso, horas después de la exposición) $)^{5,76,84,85}$.

Espectro de aumento. Se ha observado que algunos pacientes con espectro de acción en el rango de la UVA, pueden experimentar un aumento en la intensidad y la extensión de las lesiones habonosas, si son irradiados previa, simultánea o inmediatamente después con una longitud de onda mayor que la del espectro de acción. Esto se conoce como espectro de aumento; está presente en $29 \%$ de los casos con urticaria solar y podría explicar pequeños cambios en la fotosensibilidad de algunos pacientes $^{76,84,85}$.

Espectro de inhibición o de aumento. Se puede detectar al exponer un área de la piel al espectro de acción y, después, exponer la mitad de esta área inmediatamente antes o después a radiación adicional de longitudes de ondas mayores o menores. Finalmente, se comparan las áreas expuestas a una sola longitud de onda y aquellas doblemente expuestas.

\section{DIAGNÓSTICO DIFERENCIAL}

Algunos medicamentos, como los anticonceptivos orales y las tetraciclinas, pueden inducir lesiones similares a las de la urticaria solar.

Erupción solar polimorfa: el inicio de las lesiones pocos minutos después de la exposición y la resolución en pocas horas, ayudan a diferenciar la urticaria solar de la erupción solar polimorfa.

Porfiria eritropoyética: se puede presentar con lesiones urticantes después de la exposición al sol, pero se distinguen por el panel de porfirinas.

Lupus eritematoso sistémico: se puede diferenciar por el panel de los ANA y los ENA.

Urticaria crónica espontánea: no hay correlación entre la exposición a la radiación ultravioleta y la aparición de las lesiones ${ }^{7,76}$.

\section{TRATAMIENTO}

Es una de las fotodermatosis más frustrantes de tratar, debido a que incluso dosis pequeñas de radiación o exposición corta a la radiación ultravioleta o a la luz visible pueden producir lesiones, y también, debido a que los pacientes pueden tener un espectro de acción en la luz visible, lo que hace que la protección sea más difícil. Usualmente, los protectores solares de amplio espectro son inefectivos, debido a que ofrecen poca protección contra la luz visible $\mathrm{e}^{11,17,75,76}$.

Antihistamínicos: junto con los esteroides tópicos, son el tratamiento de primera línea para mejorar los síntomas. Se ha usado hidroxicina, cetirizina, fexofenadina, cimetidina y doxepina. El uso de estos agentes es importante debido a que permite que los pacientes se puedan exponer al sol, aunque hay algunos que no mejoran con los antihistamínicos ${ }^{76,86,87}$.

Ciclosporina: a dosis diarias de 3 a 4,5 mg/ $\mathrm{kg}$, fue efectiva en un caso resistente al tratamiento. Sin embargo, los habones recurrieron cuando se suspendión ${ }^{88}$.

Metotrexato: su uso en la urticaria solar no ha sido re- 
portado, pero teniendo en cuenta que es un tratamiento establecido en urticaria crónica resistente al tratamiento, podría ser una opción en estos $\operatorname{casos}^{89}$.

Inmunoglobulina IV: dosis de 1,4 a $2,5 \mathrm{mg} / \mathrm{kg}$ con infusiones en 2 a 5 dias, las cuales pueden repetirse cada 2 a 9 meses, han mostrado eficacia en urticaria resistente al tratamiento $^{76,90-92}$.

Omalizumab: ha habido reportes recientes de uso exitoso en la urticaria solar resistente al tratamiento, en dosis de $150 \mathrm{mg}$ cada dos semanas o 150-300 mg cada mes. Puede ser una opción en pacientes con aumento de la IgE que no han mejorado con otros tratamientos ${ }^{76,93,94}$.

Fototerapia: antes de iniciarla, se debe determinar la dosis mínima urticante y la dosis inicial debe ser del 50 al $70 \%$ de esta; se realizan 2 a 4 sesiones por semana durante 3 a 4 semanas, con aumentos graduales en la dosis del 10 al $20 \%$ cada dos días. En caso de presentar lesiones, se suspende la fototerapia y se inician antihistamínicos orales. A largo plazo, la PUVA ha mostrado mejores resultados que la UVB de banda estrecha, ya que su efecto es más duradero. El problema con esta modalidad de tratamiento, es que puede llevar a la aparición de síntomas sistémicos, como disnea y síncope. En aquellos pacientes con dosis mínima urticante muy baja, se puede hacer una desensibilización acelerada con UVA sin psoraleno, seis veces al día en intervalos de una hora, durante tres días consecutivos. La dosis se aumenta hasta obtener una dosis mínima urticante de 1-1,5 $\mathrm{J} / \mathrm{cm}^{2} \mathrm{y}$, en este momento, se inicia el psoraleno oral ${ }^{15-97}$.

Plasmaféresis: como en la patogénesis de la urticaria solar está implicado un fotoalérgeno, su remoción por intercambio plasmático podría ser una opción terapéutica. Su principal desventaja es que el efecto dura poco y es poco práctico para el paciente. Este tratamiento se puede combinar con $\mathrm{PUVA}^{76}$.

Alfa melanótide: es un agonista muy potente del receptor melanocortina-1. La administración exógena de este agente aumenta la melanogénesis. En el Reino Unido, a cinco pacientes se les administró una dosis única de de $16 \mathrm{mg}$ de alfa melanótide en implante subcutáneo, durante los meses de invierno. Siete días después del implante, el índice de melanina aumentó progresivamente, con un pico a los 15 días, persistiendo hasta por 60 días. Sesenta días después del implante, la dosis mínima urticante había aumentado en comparación con la del inicio, con disminución significativa de los habones. Aunque puede ser un tratamiento prometedor, se debe tener en cuenta el riesgo de un nevus displásico y melanoma, el cual debe considerarse, aunque no se ha documentado hasta ahora ${ }^{7}$.

\section{PRONÓSTICO}

Es una enfermedad crónica. La mayoría de los pacientes requiere antihistamínicos a largo plazo. La probabilidad de resolución es de $15 \%$ a los cinco años, y de $46 \%$ a los 15 años. Aquellos pacientes mayores de 40 años y con enfermedad de larga duración, tienen peor pronóstico ${ }^{77}$.

\section{HIDROA VACCINIFORME}

Es una enfermedad por fotosensibilidad poco frecuente, que ocurre principalmente en niños. Se caracteriza por una erupción vesículo-papular con posterior desarrollo de costras necróticas y cicatrices varioliformes en áreas expuestas. Ha sido clasificada como hidroa vacciniforme clásica y una forma grave llamada hidroa vaccinoide reportada principalmente en adultos, que se puede asociar con síntomas sistémicos y aumento del riesgo de desarrollar enfermedades linfoproliferativas ${ }^{76}$.

\section{EPIDEMIOLOGÍA}

Para la forma clásica, la prevalencia estimada es de 0,34 casos por 100.000 personas. Afecta principalmente los niños y las personas caucásicas. Tiene una distribución bimodal con picos entre los 1 y los 7 años, y entre los 12 y los 16 años. Predomina en hombres con una relación de 2:1, en los cuales tiene un inicio más tardío, los síntomas son más serios y es mayor la duración de la enfermedad. Por lo general, es esporádico, aunque se han reportado casos familiares $^{76,98,99}$.

\section{PATOGÉnesis}

La patofisiología de la hidroa vacciniforme es desconocida. La luz solar, especialmente la UVA, juega un papel importante. El virus de Epstein-Barr también ha sido implicado ya que se ha detectado en el infiltrado linfocítico de las lesiones de hidroa vacciniforme. Se ha encontrado, además, que abundantes copias del virus de Epstein-Barr se asocian con mayor gravedad de los síntomas y peor pronóstico ${ }^{100-102}$.

Aunque la mayoría de los casos son esporádicos, hay reportes de casos familiares, por lo que se plantea la posibilidad de que haya factores determinantes genéticos que produzcan una propensión a la enfermedad ${ }^{76}$.

\section{CLÍNICA}

La hidroa vacciniforme se inicia con la aparición de eritema y pápulo-vesículas agrupadas, simétricas y pruriginosas en áreas expuestas a la luz fotoexpuestas. Las 
lesiones pueden aparecer desde varias horas hasta dos días después de la exposición a la radiación, usualmente durante la primavera y el verano. Las pápulo-vesículas se vuelven costras que posteriormente se resuelven en 1 a 6 semanas, dejando cicatrices varioliformes. Las lesiones se localizan principalmente en áreas expuestas, como la cara (mejillas, nariz), las orejas, los antebrazos y el dorso de las manos.

En la forma grave de la hidroa vaccinoide, las lesiones son más grandes y profundas, con una distribución más extensa, incluyendo áreas no expuestas, y no siempre está asociada a fotosensibilidad. No se observa una variación con las estaciones ${ }^{76}$.

En algunos pacientes puede haber síntomas oculares, como fotofobia, epífora, conjuntivitis, uveítis o úlceras corneales. Además, en las formas graves puede haber compromiso oral, con estomatitis aftosa y gingivitis ulcerativa, úlceras del labio inferior y de la punta de la lengua $8,17,103$.

\section{DIAGNÓSTICO}

TABLA $6^{76,104,105}$

\section{DIAGNÓSTICO DIFERENCIAL}

- Porfiria eritropoyética y porfiria cutánea tarda: se pueden diferenciar por los perfiles de las porfirinas.

- Erupción juvenil de la primavera: solo afecta las orejas.

- Erupción solar polimorfa: las formas vesiculares pueden dejar cicatriz.

- $\quad$ Prurigo actínico.
- Lupus eritematoso ampolloso.

- Infección por el virus del herpes ${ }^{8,76}$.

\section{TRATAMIENTO}

Infortunadamente, no hay ningún tratamiento que haya sido universalmente efectivo. La protección solar estricta es el pilar del tratamiento. Con esta, hasta el 60 $\%$ de los pacientes mejora; del restante $40 \%$, la mitad mejora con antipalúdicos y, la otra mitad, a profilaxis durante el verano con fototerapia. En casos graves, se pueden usar los esteroides sistémicos en cursos cortos. Cuando se evidencie infección crónica por el virus de Epstein-Barr, el tratamiento antirretroviral puede reducir la gravedad y la frecuencia de las recurrencias. Con la azatioprina, la talidomida y la ciclosporina, se han obtenido resultados variables ${ }^{76,106,107}$.

\section{PRONÓSTICO}

La forma clásica se considera una enfermedad benigna con complicaciones raras y, en ocasiones, con manifestaciones sistémicas como astenia y pérdida de peso. Se resuelve generalmente en la adolescencia o la adultez temprana. Por el contrario, la forma grave o hidroa vaccinoide tiende a tener un curso clínico más largo y usualmente empeora con la edad; además, es más frecuente que presente manifestaciones sistémicas como fiebre, astenia, pérdida de peso, linfadenopatía, hepatomegalia, esplenomegalia, anormalidades de las pruebas de función hepática, leucopenia y trombocitopenia. Se sabe que los pacientes con infección crónica por el virus

\begin{tabular}{|c|c|c|}
\hline EXAMEN & RESULTADOS & COMENTARIOS \\
\hline HISTOLOGÍA & $\begin{array}{l}\text { Vesículas intraepidérmicas con células inflamatorias en } \\
\text { el interior } \\
\text { Infiltrado perivascular linfocítico } \\
\text { Las lesiones ulceradas pueden tener necrosis de la } \\
\text { epidermis y dermis superficial. }\end{array}$ & $\begin{array}{l}\text { La forma clásica y la grave } \\
\text { presentan hallazgos similares. }\end{array}$ \\
\hline \multicolumn{3}{|l|}{ FOTOTEST } \\
\hline $\begin{array}{l}\text { UVA } \\
\text { UVB } \\
\text { Luz visible }\end{array}$ & $\begin{array}{l}\text { Dosis mínima de eritema, normal o disminuida } \\
\text { Normal } \\
\text { Normal }\end{array}$ & $\begin{array}{l}\text { Espectro de acción más común: } \\
\text { UVA Dosis repetidas de UVA } \\
\text { pueden producir lesiones. }\end{array}$ \\
\hline LABORATORIO & $\begin{array}{l}\text { Porfirinas, anticuerpos antinucleares } \\
\text { Carga viral de virus de Epstein-Barr } \\
\text { Función hepática, hemoleucograma }\end{array}$ & $\begin{array}{l}\text { Sirven para diferenciarla de otros } \\
\text { diagnósticos. } \\
\text { En casos graves puede haber } \\
\text { leucopenia, trombocitopenia } \\
\text { y alteración de las pruebas de } \\
\text { función hepática. }\end{array}$ \\
\hline
\end{tabular}

TABLA 5. Diagnóstico de hidroa vacciniforme HLG: hemoleucograma, ANAS: anticuerpos antinucleares, VEB: virus epstein barr. 
de Epstein-Barr tienen una mayor probabilidad de desarrollar enfermedades linfoproliferativas; por lo tanto, los pacientes con la variante grave de hidroa vacciniforme pueden tener mayor riesgo de progresión a linfomas malignos asociados al virus de Epstein-Barr ${ }^{76,108,109}$.

\section{CONCLUSIÓN}

Las fotodermatosis mediadas inmunológicamente son precipitadas por la radiación electromagnética, principalmente la radiación ultravioleta o la luz visible. La historia clínica y el examen físico usualmente ayudan en el diagnóstico. Los estudios fotobiológicos son las herramientas más importantes para confirmar el diagnóstico y determinar el espectro de acción. No hay un tratamiento curativo. La protección solar es la medida principal para la prevención de estas fotodermatosis. Además, los esquemas de fototerapia pueden aumentar la tolerancia a la radiación ultravioleta. Sin embargo, en las formas graves se requieren tratamientos inmunomoduladores para controlar la enfermedad.

\section{REFERENCIAS}

1. Rizwan M, Reddick CL, Bundy C, Unsworth R, Richards HL, Rhodes LE. Photodermatoses: Environmentally induced conditions with high psychological impact. Photochem Photobiol Sci 2013;12:182-9.

2. Choi D, Kannan S, Lim H. Evaluation of patients with photodermatoses. Dermatol Clin. 2014,32:267-75.

3. Bylaite M, Grigaitiene J, Lapinskaite GS. Photodermatoses: Classification, evaluation and management. Br J Dermatol. 2009;161:61-8.

4. Yashar SS, Lim HW. Classification and evaluation of photodermatoses. Dermatol Ther. 2003;16:1-7.

5. De Argila D, Aguilera J, Sánchez J, García-Díez A. Study of idiopathic, exogenous photodermatoses. Part II: Photobiologic testing. Actas Dermosifiliogr. 2014;105:233-42.

6. De Argila D, Aguilera J, Sánchez J, García-Díez A. Study of idiopathic, exogenous photodermatoses. Part I: Pathophysiology and technical aspects of photobiologic studies. Actas Dermosifilogr. 2014;105:112-21.

7. Lehmann P, Schwarz T. Photodermatoses: Diagnosis and treatment. Dtsch Arztebl Int. 2011;108:135-41.

8. Gambichler T, Al-Muhhammadi R, Bomms S. Immunologically mediated photodermatoses. Am J Clin Dermatol. 2009;10:16980 .

9. Trakatelli M, Charalampidis S, Novakovic LB. Photodermatoses with onset in the elderly. Br J Dermatol. 2009;161:69-77.

10. Roelandts R. Diagnosis and treatment of solar urticaria. Dermatol Ther. 2003;16:52-6.

11. Morales N, Zapata F, Zuluaga MA, Mendoza N, Uribe MP, Jiménez SB. Fotodermatosis y terapia de desensibilización. Revista CES Medicina. 2012;26:29-41,
12. Grossber AL. Update on pediatric photosensitivity disorders. Curr Opin Pediatr. 2013;25:474-9.

13. Stratigos AJ, Antoniou C, Katsambas AD. Polymorphous light eruption. J Eur Acad Dermatol Venereol. 2002;16:193-206.

14. Gruber-Wackermagel A, Byrne SN, Wolf P. Polymorphous light eruption: Clinic aspects and pathogenesis. Dermatol Clin. 2014;32:315-34.

15. Wolf P, Byrne SN, Gruber-Wackernagel A. New insights into the mechanisms of polymorphic light eruption: Resistance to ultraviolet radiation induced immune suppression as an aetiological factor. Exp Dermatol.2009;18:350-6.

16. Elmets CA, Cala CM, Xu H. Photoimmunology. Dermatol Clin. 2014;32:277-90.

17. Lecha M. Idiopathic photodermatoses: Clinical, diagnostic and therapeutic aspects. Eur Acad Dermatol Venereol. 2001;15:499-505.

18. Lava SA, Simonetti GD, Ragazzi M, Guarino Gubler S, Bianchetti MG. Juvenile spring eruption: An outbreak report and systematic review of the literature. Br J Dermatol. 2013;168:1066-72.

19. Ros AM. Solar purpura -an unusual manifestation of polymorphous light eruption. Photodermatol. 1988;5:47-8.

20. Kalivas J, Kalivas L. Solar purpura appearing in a patient with polymorphous light eruption. Photodermatol Photoimmunol Photomed. 1995;11:31-2.

21. Jansen CT, Karvonen J. Polymorphous light eruption. A sevenyear follow-up evaluation of 114 patients. Arch Dermatol. 1984;120:862-5.

22. Murphy GM, Hawk JL. The prevalence of antinuclear antibodies in patients with apparent polymorphic light eruption. Br J Dermatol. 1991;125:448-51.

23. Petzelbauer P, Binder M, Nikolakis P, Ortel B, Honigsmann H. Severe sun sensitivity and the presence of antinuclear antibodies in patients with polymorphous light eruption-like lesions. A form fruste of photosensitive lupus erythematosus? J Am Acad Dermatol. 1992;26:68-74.

24. Hasan T, Ranki A, Jansen CT, Karvonen J. Disease associations in polymorphous light eruption. A longterm follow-up study of 94 patients. Arch Dermatol. 1998;134:1081-5.

25. Mastalier U, Kerl H, Wolf P. Clinical, laboratory, phototest and phototherapy findings in polymorphic light eruptions: A retrospective study of 133 patients. Eur J Dermatol. 1998;8:554-9.

26. Tzaneva S, Volc-Platzer B, Kittler H, Honigsmann H, Tanew A. Antinuclear antibodies in patients with polymorphic light eruption: A long-term follow-up study. Br J Dermatol. 2008;158:1050-4.

27. Stratigos AJ, Antoniou C, Katsambas AD. Polymorphous light eruption. J Eur Acad Dermatol Venerol. 2002;16:193-206.

28. Honigsmann H. Polymorphous light eruption. Photodermatol Photoimmunol Photomed. 2008;24:155-61.

29. Patel DC, Bellaney GJ, Sedd PT, McGregor JM, Hawk JL. Efficacy of short-course oral prednisolone in polymorphic light eruption: A randomized controlled trial. Br J Dermatol. 2000;143:828-31.

30. Pareek A, Khopkar U, Sacchidanand S, Chandurkar N, Naik GS. Comparative study of efficacy and safety of hydroxychloroquine and chloroquine in polymorphic light eruption: A randomized, double-blind, multicentric study. Indian J Dermatol Venerol Leprol. 2008;74:18-22.

31. Rodríguez C, Marsol I. Antimalarials in dermatology: Mechanism of action, indications, and side effects. Actas Dermosifiliogr. 2014;105:243-52. 
32. Wolf R, Wolf D, Ruocco V. Antimalarials: Unapproved uses or indications. Clin Dermatol. 2000;18:17-35.

33. Honigsmann H. Mechanisms of phototherapy and photochemotherapy for photodermatoses. Dermatol Ther. 2003;16:23-7.

34. Caccialanza M, Percivalle S, Piccinno R, Brambilla R. Photoprotective activity of oral Polypodium leucotomos extract in 25 patients with idiopathic photodermatoses. Photodermatol Photoimmunol Photomed. 2007;23:46-7.

35. Hanneman KK, Scull HM, Cooper KD, Baron ED. Effect of topical vitamin $\mathrm{D}$ analogue on in vivo contact sensitization. Arch Dermatol. 2006;142:1332-4.

36. Valbuena MC, Muvdi S, Lim HW. Actinic prurigo. Dermatol Clin. 2014;32:335-44.

37. Hojyo-Tomoka MT, Vega-Memije ME, Cortés-Franco R. Diagnosis and treatment of actinic prurigo. Dermatol Ther. 2003;16:40-4.

38. Ferguson J. Diagnosis and treatment of the common idiopathic photodermatoses. Australas J Dermatol. 2003;44:90-6.

39. Lane PR, Hogan DJ, Martel MJ, Reeder B, Irvine J. Actinic prurigo: Clinical features and prognosis. J Am Acad Dermatol. 1992;26:683-92.

40. Torres-Álvarez B, Baranda L, Fuentes C, Delgado C, SantosMartínez L, Portales-Pérez D, et al. An immunohistochemical study of UV-induced skin lesions in actinic prurigo. Resistance of Langerhans cells to UV light. Eur J Dermatol. 1998;8:24-8.

41. Menage $\mathrm{H}$ du P, Vaughan RW, Baker CS, Page G, Proby CM, Breathbach SM, et al. HLADR4 may determine expression of actinic prurigo in British patients. J Invest Dermatol. 1996;106:362-7.

42. Zuluaga-Salcedo S, Castillo-Vázquez M, Vega-Memije E, Arellano-Campos O, Rodríguez-Pérez JM, Pérez Hernández $\mathrm{N}$, et al. Class I and class II major histocompatibility complex genes in Mexican patients with actinic prurigo. Br J Dermatol. 2007;156:1074-5.

43. Suárez A, Valbuena MC, Rey M, Porras L. Association of HLA subtype DRB10407 in Colombian patients with actinic prurigo. Photodermatol Photoimmunol Photomed. 2006;22:55-8.

44. Wiseman MC, Orr PH, Macdonald SM, Schroeder ML, Toole JW. Actinic prurigo: Clinical features and HLA associations in a Canadian Inuit population. J Am Acad Dermatol. 2001;44:952-6.

45. Magaña M, Méndez Y, Rodríguez A, Mascott M. The conjunctivitis of solar (actinic) prurigo. Pediatr Dermatol. 2000;17:432-5.

46. Vega-Memije ME, Mosqueda-Taylor A, Iriqoyen-Camacho ME. Actinic prurigo cheilitis: Clinic-pathologic analysis and therapeutic results in 116 cases. Oral Surg Oral Med Oral Pathol Oral Radiol Endod. 2002;94:83-91.

47. Herrera-Geopfert R, Magaña M. Follicular cheilitis. A distinctive histopathologic finding in actinic prurigo. Am J Dermatopathol. 1995;17:357-61.

48. Miranda AM, Ferrari TM, Werneck JT, Junior AS, Cunha KS, Dias EP. Actinic prurigo of the lip: Two case reports. World J Clin Cases. 2014;2:385-90.

49. Ross G, Foley P, Baker C. Actinic prurigo. Photodermatol Photoimmunol Photomed. 2008;24:272-5.

50. González-Carrascosa M, De la Cueva DP, Hernanz-Hermosa JM, Chavarría-Mur E. Tratamiento del prurigo actínico con tacrolimus al o,1\%. Med Cutan Ibero Lat Am. 2006;34:233-6.

51. Wu JJ, Huang DB, Pang KR, Hsu S, Tyring SK. Thalidomide: Dermatological indications, mechanisms of action and sideeffects. Br J Dermatol. 2005;153:254-73.
52. Chen M, Doherty SD, Hsu S. Innovative uses of thalidomide. Dermatol Clin. 2010;28:577-86.

53. Jacobson J. Thalidomide: A remarkable comeback. Expert Opin Pharmacother. 2000;1:849-63.

54. Estrada I, Garibay-Escobar A, Núñez-Vásquez A, Hojyo-Tomoka T, Vega-Memije E, Cortés-Franco R, et al. Evidence that thalidomide modifies the immune response of patients suffering from actinic prurigo. Int J Dermatol. 2004;43:893-7.

55. Yong-Gee SA, Muir JB. Long-term thalidomide for actinic prurigo. Australas J Dermatol. 2001;42:281-3

56. Umaña A, Gómez A, Durán MM, Porras L. Lymphocyte subtypes and adhesion molecules in actinic prurigo: Observations with cyclosporin A. Int J Dermatol. 2002;41:139-45.

57. Torres-Álvarez B, Castanedo-Cazares JP, Moncada B. Pentoxifylline in the treatment of actinic prurigo. A preliminary report of 10 patients. Dermatology. 2004;208:198-201.

58. Grossberg AL. Update on pediatric photosensitivity disorders. Curr Opin Pediatr. 2013;25:474-9.

59. Paek SY, Lim HW. Chronic actinic dermatitis. Dermatol Clin. 2014;32:355-61.

6o. Tan AW, Lim KS, Theng C, Chong WS. Chronic actinic dermatitis in Asian skin: A Singaporean experience. Photodermatol Photoimmunol Photomed. 2011;27:172-5.

61. Creamer D, McGregor JM, Hawk JL. Chronic actinic dermatitis occurring in young patients with atopic dermatitis. Br J Dermatol. 1998;139:1112-3.

62. Meola T, Sánchez M, Lim HW, Buchness MR, Soter NA. Chronic actinic dermatitis associated with human immunodeficiency virus infection. Br J Dermatol. 1997;137:431-6.

63. Beach RA, Pratt MD. Chronic actinic dermatitis: Clinical cases, diagnostic workup, and therapeutic management. J Cutan Med Surg. 2009;13:121-2.

64. Menage HD, Harrison GI, Potten CS, Young AR, Hawak JL. The action spectrum for induction of chronic actinic dermatitis is similar to that for sunburn inflammation. Photochem Photobiol. 1995;62:976-8.

65. Somani VK. Chronic actinic dermatitis-a study of clinical features. Indian J Dermatol Venereol Leprol. 2005;71:409-13.

66. Pacheco D, Fraga A, Travassos AR, Antunes J, Fretas J, Soares de Almeida L, et al. Actinic reticuloid imitating Sezary syndrome. Acta Dermato Venerol. 2012;21:55-7.

67. Uetsu N, Okamoto H, Fujii K, Doi R, Horio T. Treatment of chronic actinic dermatitis with tacrolimus ointment. J Am Acad Dermatol. 2002;47:881-4.

68. Grone D, Kunz M, Zimmermann R, Gross G. Successful treatment of nodular actinic reticuloid with tacrolimus ointment. Dermatology. 2006;212:377-80.

69. Stinco G, Codutti R, Frattasio A, De Francesco V, Patrone P. Chronic actinic dermatitis treated with cyclosporine A. Eur J Dermatol. 2002;12:455-7.

70. Murphy GM, Maurice PD, Norris PG, Morris RW, Hawk JL. Azathioprine treatment in chronic actinic dermatitis: A doubleblind controlled trial with monitoring of exposure to ultraviolet radiation. Br J Dermatol. 1989;121:639-46.

71. Thomson MA, Stewart DG, Lewis HM. Chronic actinic dermatitis treated with mycophenolate mofetil. Br J Dermatol. 2005;152:784-6.

72. Safa G, Piéto-LE, Corvaisier C, Hervagault B. Recalcitrant chronic actinic dermatitis treated with low-dose thalidomide. J Am Acad Dermatol. 2005;52:E6. 
73. Rose RF, Goulden V, Wilkinson SM. The spontaneous resolution of photosensitivity and contact allergy in a patient with chronic actinic dermatitis. Photodermatol Photoimmunol Photomed. 2009;25:114-6.

74. Sugita K, Shimauchi T, Tokura Y. Chronic actinic dermatitis associated with adult T-cell leukemia. J Am Acad Dermatol. 2005;52(Suppl.1):38-40.

75. Botto NC, Warshaw EM. Solar urticaria. J Am Acad Dermatol. 2008;59:909-20.

76. Nitiyaram R, Wongpraparut C. Hydroa vaccinifrome and solar urticaria. Dermatol Clin. 2014;32:345-53.

77. Beattie PE, Dawe RS, Ibbotson SH, Ferquson J. Characteristics and prognosis of idiopathic solar urticaria: A cohort of 87 cases. Arch Dermatol. 2003;139:1149-54.

78. Beattie PE, Dawe RS, Ibbotson SH, Ferquson J. Co-existence of chronic actinic dermatitis and solar urticaria in three patients. Br J Dermatol. 2004;151:513-5.

79. Yu RC, King CM, Vickers CF. A case of actinic prurigo and solar urticaria. Clin Exp Dermatol. 1990;15:289-92.

8o. Dawe RS, Clark C, Ferguson J. Porphyria cutanea tarda presenting as solar urticaria. Br J Dermatol. 1999;141:590-1.

81. Leenutaphong V, Holzle E, Plewig G. Pathogenesis and classification of solar urticaria: A new concept. J Am Acad Dermatol. 1989;21:237-40.

82. Reinauer S, Leenutaphong V, Holzle E. Fixed solar urticaria. J Am Acad Dermatol. 1993;29:161-5.

83. Wessendorf U, Hanneken S, Haust M, Neumann NJ. Fixed solar urticaria with delayed onset. J Am Acad Dermatol. 2009;60:695-7.

84. Watanabe M, Matsunaga Y, Katayama I. Solar urticaria: A consideration of the mechanism of inhibition spectra. Dermatology. 1999;198:252-5.

85. Fukunaga A, Horikawa T, Yamamoto A, Yamada Y, Nishigori C. The inhibition spectrum of solar urticaria suppresses the whealflare response following intradermal injection with photoactivated autologous serum but not with compound 48/80. Photodermatol Photoimmunol Photomed. 2006;22:129-32.

86. Neittaanmaki H, Jaaskelainen T, Harvima RJ, Frakj JE. Solar urticaria: Demonstration of histamine release and effective treatment with doxepin. Photodermatol. 1989;6:52-5

87. Tokura Y, Takigawa M, Yamauchi T, Yamada M. Solar urticaria: A case with good therapeutic response to cimetidine. Dermatologica. 1986;173:224-8.

88. Edstrom DW, Ros AM. Cyclosporin A therapy for severe solar urticaria. Photodermatol Photoimmunol Photomed. 1997;13:61-3.

89. Pérez A, Woods A, Grattan CE. Methotrexate: A useful steroidsparing agent in recalcitrant chronic urticaria. Br J Dermatol. 2010;162:191-4.

90. Mitzel-Kaoukhov H, Staubach P, Muller-Brenne T. Effect of high-dose intravenous immunoglobulin treatment in therapyresistant chronic spontaneous urticaria. Ann Allergy Asthma Immunol. 2010;104:253-8.

91. Correia I, Silva J, Filipe P, Gomes M. Solar urticaria treated successfully with intravenous high-dose immunoglobulin: A case report. Photodermatol Photoimmunol Photomed. 2008;24:330-1.

92. Adamski H, Bedane C, Bonnevalle A, Thomas P, Peyron JL, Rouchouse B, et al. Solar urticaria treated with intravenous immunoglobulins. J Am Acad Dermatol. 2011;65:336-40.
93. Waibel KH, Reese DA, Hamilton RG, Devillez RL. Partial improvement of solar urticaria after omalizumab. J Allergy ClinImmunol. 2010;125:490-1.

94. Metz M, Altrichter S, Ardelean E, Kessler B, Krause K, Magerl $\mathrm{M}$, et al. Anti-immunoglobulin E treatment of patients with recalcitrant physical urticaria. Int Arch Allergy Immunol. 2011;154:177-80.

95. Masuoka E, Fukunaga A, Kishigami K, Jimbo H, Nishioka M, Uchimura Y, et al. Successful and long-lasting treatment of solar urticaria with ultraviolet A rush hardening therapy. $\mathrm{Br} J$ Dermatol. 2012;167:198-201.

96. Beissert S, Stander H, Schwarz T. UVA rush hardening for the treatment of solar urticaria. J Am Acad Dermatol. 2000;42:1030.

97. Wolf R, Herzinger T, Grahovac M, Prinz JC. Solar urticaria: Long-term rush hardening by inhibition spectrum narrow-band UVB 311 nm. Clin Exp Dermatol. 2013;38:446-7.

98. Gupta G, Man I, Kemmett D. Hydroavacciniforme: A clinical and follow-up study of 17 cases. J Am Acad Dermatol. 2000;42:20813.

99. Gupta G, Mohamed M, Kemmett D. Familial hydroa vacciniforme. Br J Dermatol. 1999;140:124-6.

100. Verneuil L, Gouarin S, Comoz F, Aqbalika F, Creveuil C, Varna $\mathrm{M}$, et al. Epstein-Barr virus involvement in the pathogenesis of hydro avacciniforme: An assessment of seven adult patients with long-term follow-up. Br J Dermatol. 2010;163:174-82.

101. Mendoza N, Diamantis M, Arora A, Bartlett B, Gewirtzman A, Tremaine AM, et al. Mucocutaneous manifestations of EpsteinBarr virus infection. Am J Clin Dermatol. 2008;9:295-305.

102. Iwatsuki K, Satoh M, Yamamoto T, Oono T, Morizane S, Ohtsuka $\mathrm{M}$, et al. Pathogenic link between hydroa vacciniforme and Epstein-Barr virus-associated hematologic disorders. Arch Dermatol. 2006;142:587-95.

103. Yamamoto T, Hirai Y, Miyake T, Tamasaki O, Morizane S, Iwatsuki K. Oculo-mucosal and gastrointestinal involvement in Epstein-Barr virus-associated hydroa vacciniforme. Eur J Dermatol. 2012;22:380-3.

104. Lee HY, Baek JO, Lee JR, Park SH, Jeon IS, Roh JY, et al. Atypical hydroa vacciniforme-like Epstein-Barr virus associated T/NK-cell lymphoproliferative disorder. Am J Dermatopathol. 2012;34:e119-24.

105. Sonnex TS, Hawk JL. Hydroa vacciniforme: A review of ten cases. Br J Dermatol. 1988;118:101-8.

106. Huggins RH, Leithauser LA, Eide MJ, Hexsel CL, Jacobsen G Lim HW. Quality of life assessment and disease experience of patient members of a web-based hydroa vacciniforme support group. Photodermatol Photoimmunol Photomed. 2009;25:20915 .

107. Lysell J, Wiegleb Edstrom D, Linde A, Carlsson G, MalmrosSvennilson J, Westermark A, et al. Antiviral therapy in children with hydroa vacciniforme. Acta Derm Venereol. 2009;89:393-7.

108. Oono T, Arata J, Masuda T, Ohtsuki Y. Coexistence of hydroa vacciniforme and malignant lymphoma. Arch Dermatol. 1986;122:1306-9.

109. Quintanilla-Martínez L, Ridaura C, Nagl F, Sáez-de-Ocariz M, Duráan-McKinster C, Ruiz-Maldonado R, et al. Hydroa vacciniforme-like lymphoma: A chronic EBV1 lymphoproliferative disorder with risk to develop a systemic lymphoma. Blood. 2013;122:3101-10. 